\title{
SINTESIS NANOMATERIAL MAGNETIT-SITRAT DAN PENGUJIAN APLIKASINYA SEBAGAI ADSORBEN EMAS (III)
}

\author{
Susanto dan Ricka Prasdiantika \\ Fakultas Teknik Universitas Pandanaran Semarang \\ Email: susanto.chem@gmail.com \\ Theodor C.M. Bolle \\ Fakultas Sains dan Teknik Universitas Nusa Cendana Kupang \\ Email: caesarmarhenyo@yahoo.co.id
}

\begin{abstract}
This study aims to synthesize magnetite nanomaterial that dispersed with trisodium citrate ( $\mathrm{Fe}_{3} \mathrm{O}_{4} @ \mathrm{citrate}$ ), to conduct the characterization, and to test its application in adsorbing of $\mathrm{Au}(\mathrm{III})$. Research condcuts by synthesis of $\mathrm{Fe}_{3} \mathrm{O}_{4}$ with stirring using ultrasonic waves to synthesis of magnetite in the system of co-precipitation, to use sodium citrate as dispersing agent of magnetite, and to use acetone-water as solvent at washing of magnetite. Synthesized product is characterized by Fourier Transform Infrared spectrophotometer (FTIR), X-ray diffractometer (XRD), and transmission electron microscope (TEM). The characterized results indicate that $\mathrm{Fe}_{3} \mathrm{O}_{4} @$ citrate has successfully synthesized with particle size of $17 \mathrm{~nm} . \mathrm{Fe}_{3} \mathrm{O}_{4} @$ citrate has smaller particle size, has smaller aggregates and has better particle dispersion than $\mathrm{Fe}_{3} \mathrm{O}_{4}$ without citrate. Testing the potential of synthesized $\mathrm{Fe}_{3} \mathrm{O}_{4} @$ citrate as adsorbent of $\mathrm{Au}(\mathrm{III})$ from $\mathrm{HAuCl}_{4}$ solution of $200 \mathrm{ppm}$ at $\mathrm{pH}$ 3. the Synthesized $\mathrm{Fe}_{3} \mathrm{O}_{4} @$ citrate adsorbe the gold(III) of (81.554 \pm 1.403$) \mathrm{mg} / \mathrm{g}$.
\end{abstract}

Keywords: Adsorbent; Dispersions particle; Gold (III); Magnetite; Nanomaterial; Sodium citrate.

\begin{abstract}
ABSTRAK
Penelitian ini bertujuan untuk mensintesis nanomaterial magnetit yang terdispersi natrium sitrat $\left(\mathrm{Fe}_{3} \mathrm{O}_{4} @\right.$ sitrat), melakukan karakterisasi, dan menguji aplikasinya dalam mengadsorpsi Au(III). Penelitian dilakukan dengan mensintesis $\mathrm{Fe}_{3} \mathrm{O}_{4}$ dengan pengadukan menggunakan gelombang ultrasonik untuk sintesis magnetit pada sistem co-presipitasi, menggunakan natrium sitrat sebagai agen pendispersi magnetit, dan menggunakan aseton-air sebagai pelarut pada pencucian magnetit. Produk sintesis dikarakterisasi dengan fourier transform infrared spectrophotometer (FTIR), X-ray diffractometer (XRD), dan transmission electron microscope (TEM). Hasil karakterisasi mengindikasikan bahwa $\mathrm{Fe}_{3} \mathrm{O}_{4} @$ sitrat telah berhasil disintesis dengan ukuran $17 \mathrm{~nm}$. $\mathrm{Fe}_{3} \mathrm{O}_{4} @$ sitrat memiliki ukuran partikel lebih kecil, membentuk agregat lebih kecil dan memiliki dispersi partikel yang lebih baik dibandingkan $\mathrm{Fe}_{3} \mathrm{O}_{4}$ tanpa sitrat. Pengujian aplikasi $\mathrm{Fe}_{3} \mathrm{O}_{4} @$ sitrat hasil sintesis sebagai adsorben emas(III) dari larutan $\mathrm{HAuCl}_{4} 200 \mathrm{ppm}$ pada $\mathrm{pH} 3 . \mathrm{Fe}_{3} \mathrm{O}_{4} @_{\text {@itrat hasil }}$ sintesis mampu mengadsorpsi emas(III) sebanyak $(81,554 \pm 1,403) \mathrm{mg} / \mathrm{g}$.
\end{abstract}

Kata Kunci: Adsorben; Dispersi partikel; Emas (III); Magnetit; Nanomaterial; Natrium sitrat. 


\section{PENGANTAR}

Nanomaterial yang memiliki ukuran partikel 1-100 nm menarik untuk diteliti karena sifat fisika dan kimianya yang berbeda dari partikel bulky [1]. Magnetit $\left(\mathrm{Fe}_{3} \mathrm{O}_{4}\right)$ merupakan magnetik nanomaterial yang sangat menarik untuk diteliti karena sifatnya yang superparamagnetik dan memiliki kadar toksik yang rendah [2], selain itu juga memiliki karakteristik seperti nilai titik poin (saturasi) magnetik yang tinggi serta respon magnetik yang baik [3].

$\mathrm{Fe}_{3} \mathrm{O}_{4}$ memiliki potensi aplikasi dalam bidang drug delivery dan agen kontras pada magnetic resonance imaging (MRI) [2,4]. $\mathrm{Fe}_{3} \mathrm{O}_{4}$ mempermudah pemisahan adsorben dari larutannya pada sistem Batch [5].

$\mathrm{Fe}_{3} \mathrm{O}_{4}$ mudah mengalami agregasi [6], mudah teroksidasi karena memiliki ion $\mathrm{Fe}^{2+}$ [7], dan tidak stabil pada kondisi asam [5]. Modifikasi permukaan $\mathrm{Fe}_{3} \mathrm{O}_{4}$ dengan agen pendispersi diperlukan untuk meningkatkan stabilitas dispersi pada media reaksi sehingga $\mathrm{Fe}_{3} \mathrm{O}_{4}$ memiliki dispersi yang baik dengan struktur yang bagus [8]. Senyawa yang dapat digunakan sebagai agen pendispersi $\mathrm{Fe}_{3} \mathrm{O}_{4}$ adalah natrium sitrat dengan pencucian menggunakan aseton [7]. Namun penggunaan aseton yang terlalu banyak kurang ramah lingkungan. Oleh karena itu pada penelitian ini digunakan pelarut aseton-air.

Emas merupakan logam mulia yang permintaan pasarnya selalu meningkat [5]. Emas memiliki kegunaan dalam bidang industri perhiasan, industri elektronik [9], dan industri kimia [10]. Adsorpsi merupakan salah satu teknik yang menjanjikan untuk pemisahan emas karena menggunakan peralatan yang sederhana, biaya murah, dan lebih efisien karena dapat diaplikasikan pada konsentrasi ion logam yang rendah [11]. Adsorpsi didasarkan pada interaksi ion logam dengan gugus fungsional seperti gugus hidroksida $(-\mathrm{OH})$, gugus karboksilat $(-\mathrm{COOH})$, gugus amina $(-\mathrm{NH})$, dan gugus merkapto (-SH) yang ada pada permukaan adsorben yang salah satunya melalui interaksi pembentukan kompleks [12]. Magnetit-sitrat yang telah disintesis dimungkinkan memiliki gugus fungsional hidroksida dan karboksilat pada kondisi asam. Magnetit-sitrat $\left(\mathrm{Fe}_{3} \mathrm{O}_{4} @\right.$ sitrat) dapat digunakan untuk mengadsorpsi ion logam berat seperti ion logam $\mathrm{Cd}(\mathrm{II})$ dan $\mathrm{Cr}(\mathrm{VI})$ [13], namun belum digunakan untuk mengadsorpsi ion logam Au(III). Pada penelitian ini dilakukan pengujian aplikasi $\mathrm{Fe}_{3} \mathrm{O}_{4} @$ sitrat dalam mengadsorpsi ion logam $\mathrm{Au}(\mathrm{III})$.

Tulisan ini dilakukan sintesis magnetitsitrat pada sistem co-presipitasi dengan metode sonokimia dan menggunakan natrium sitrat sebagai agen pendispersi magnetit.

\section{Metode}

Pembuatan magnetit pada penelitian ini menggunakan bahan-bahan dari Merck yang terdiri dari $\mathrm{FeCl}_{3} \cdot 6 \mathrm{H}_{2} \mathrm{O}, \mathrm{FeCl}_{2} \cdot 4 \mathrm{H}_{2} \mathrm{O}, \mathrm{NH}_{3} 25 \%$, aseton, dan $\mathrm{HCl} 37 \%$ serta menggunakan bahan dari Aldrich berupa natrium sitrat.

Peralatan yang digunakan pada penelitian ini meliputi alat preparasi dan peralatan analisis. Alat preparasi terdiri dari gelas ukur berbagai ukuran, labu ukur berbagai ukuran, gelas Beaker dengan berbagai ukuran, labu Erlenmeyer, kertas $\mathrm{pH}$ universal, lumpang dan mortar porselen, Ultrasonic Branson 3210 (48 $\mathrm{kHz}, 220$ Volt), oven (Fischer Scientific), neraca analitik (Metter AE 160), magnet eksternal (Niobium) dan shaker (VRN-200).

Alat analisis terdiri dari fourier transform infrared spectrophotometer (FTIR, Shimadzu Prestige 21) untukidentifikasi gugus fungsional magnetit hasil sintesis, X-ray diffractometer (XRD, XRD-6000 Shimadzu) untuk identifikasi jenis mineral magnetik dan ukuran magnetit sintesis, Transmission Electron Microscope (TEM, JEOL TEM-1400) untuk mengamati dispersi partikel magnetit hasil sintesis, Atomic Absorption Spectoscopy (AAS, Perkin Elmer AA 3110) untuk menganalisis konsentrasi logam Au total yang teradsorpsi.

\section{Prosedur Kerja}

\section{Sintesis Nanomaterial $\mathrm{Fe}_{3} \mathrm{O}_{4} @$ sitrat} [7]:

Sintesis magnetit berdasarkan persamaan

$$
\mathrm{Fe}^{2+}+2 \mathrm{Fe}^{3+}+8 \mathrm{OH}^{-} \rightarrow \mathrm{Fe}_{3} \mathrm{O}_{4}+4 \mathrm{H}_{2} \mathrm{O} .
$$


Sintesis magnetit dilakukan dengan cara ke dalam gelas Beaker yang berisi $100 \mathrm{~mL}$ air dialiri gas $\mathrm{N}_{2}$ selama 1 menit, kemudian dilarutkan sebanyak $5,40 \mathrm{~g} \quad \mathrm{FeCl}_{3} \cdot 6 \mathrm{H}_{2} \mathrm{O}$, setelah itu larutan disonikasi sambil dialiri gas $\mathrm{N}_{2}$, kemudian sebanyak 2,78 $\mathrm{g} \mathrm{FeCl}_{2} \cdot 4 \mathrm{H}_{2} \mathrm{O}$ ditambahkan ke dalam larutan. Larutan tersebut kemudian ditambahkan $15 \mathrm{~mL} \mathrm{NH}_{3}$ $25 \%$ tetes demi tetes sambil disonikasi. Sonikasi dengan aliran gas $\mathrm{N}_{2}$ dilanjutkan sampai 60 menit. Kemudian dilakukan penyimpanan (aging) selama 24 jam. Endapan yang terbentuk dipisahkan dari filtratnya dengan magnet eksternal. Endapan yang terbentuk direndam dalam $100 \mathrm{~mL}$ larutan natrium sitrat $0,5 \mathrm{M}$. Campuran tersebut disonikasi selama 60 menit, lalu dilakukan aging selama 24 jam. Endapan kemudian dipisahkan dari filtratnya menggunakan magnet eksternal. Endapan dicuci dengan aseton, kemudian dicuci dengan air. Setiap pencucian disonikasi selama 30 menit. Kemudian endapan dipisahkan menggunakan magnet eksternal, lalu dikeringkan pada suhu $75^{\circ} \mathrm{C}$. Magnetit hasil sintesis yang diperoleh dilakukan karakterisasi dengan FTIR spectrophotometer, XRD, dan TEM. Sintesis magnetit tanpa natrium sitrat yang dicuci dengan air dilakukan sebagai magnetit pembanding.

\section{Pengujian Aplikasi $\mathrm{Fe}_{3} \mathrm{O}_{4} @$ sitrat dalam Mengadsorpsi Au(III)}

Sebanyak10 mg Fe $\mathrm{O}_{4} @$ sitrat ditempatkan dalam botol plastik. Adsorpsi dilakukan dalam sistem batch dengan cara menambahkan $10 \mathrm{ml}$ larutan $\mathrm{HAuCl}_{4} 200$ ppm dengan $\mathrm{pH} 3$ pada botol plastik. Campuran larutan $\mathrm{HAuCl}_{4}$ dan $\mathrm{Fe}_{3} \mathrm{O}_{4} @$ sitrat digojog dengan shaker selama 120 menit. Kemudian supernatan (filtrat) dan adsorben dipisahkan menggunakan magnet eksternal. Supernatan dianalisis dengan AAS untuk menentukan konsentrasi total logam $\mathrm{Au}$ yang teradsorpsi.

\section{HASIL DAN PEMBAHASAN}

Magnetit tanpa Sitrat $\left(\mathrm{Fe}_{3} \mathrm{O}_{4}\right)$ dan Magnetit-sitrat ( $\mathrm{Fe}_{3} \mathrm{O}_{4} @$ sitrat) hasil sintesis dikarakterisasi dengan FTIR, XRD, dan TEM. Spektra inframerah digunakan untuk mengidentifikasi terbentuknya $\mathrm{Fe}_{3} \mathrm{O}_{4}$ dan $\mathrm{Fe}_{3} \mathrm{O}_{4} @$ sitrat hasil sintesis. Hasil karakterisasi magnetit hasil sintesis yang dilakukan ditunjukan pada Gambar 1.

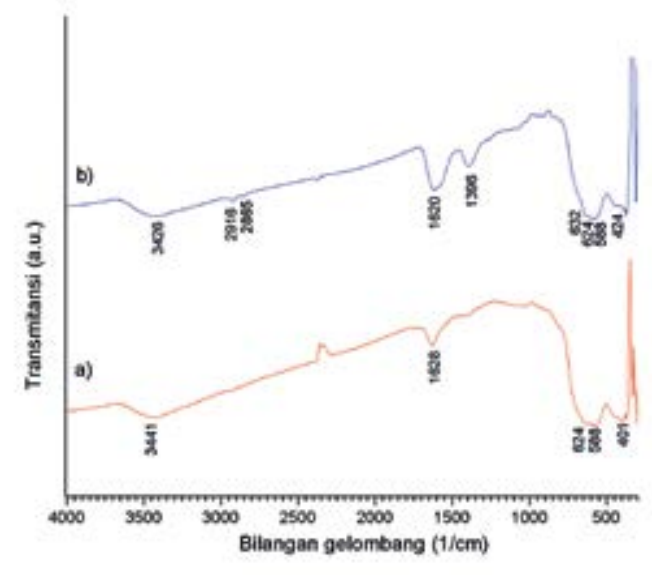

Gambar 1.

Spektra Inframerah: a) $\mathrm{Fe}_{3} \mathrm{O}_{4}$ dan b) $\mathrm{Fe}_{3} \mathrm{O}_{4} @$ sitrat

Berdasarkan pada Gambar 1, bilangan gelombang pada $\left(401-424,588\right.$, dan 624) $\mathrm{cm}^{-1}$ mengindikasikan adanya vibrasi ulur $\mathrm{Fe}-\mathrm{O}$ [14]. Bilangan gelombang pada $632 \mathrm{~cm}^{-1}$ mengindikasikan adanya interaksi $\mathrm{Fe}$ dengan -COO- sitrat [15]. Bilangan gelombang pada $1396 \mathrm{~cm}^{-1}$ mengindikasikan adanya vibrasi ulur simetris-COO- dari gugus sitrat [7]. Bilangan gelombang pada $1620 \mathrm{~cm}^{-1}$ mengindikasikan adanya vibrasi ulur asimetris - $\mathrm{COO}^{-}$sitrat yang tumpang tindih vibrasi ulur $-\mathrm{OH}$ dari gugus sitrat serta permukaan magnetit yang berinteraksi dengan air [7]. Bilangan gelombang pada $1628 \mathrm{~cm}^{-1}$ mengindikasikan adanya vibrasi ulur $-\mathrm{OH}$ dari air [7]. Bilangan gelombang pada $2855 \mathrm{~cm}^{-1}$ dan $2916 \mathrm{~cm}^{-1}$ mengindikasikan adanya vibrasi ulur simetris dan asimetris $\mathrm{C}-\mathrm{H}$ [16]. Bilangan gelombang pada $3426-3441 \mathrm{~cm}^{-1}$ mengindikasikan adanya vibrasi ulur $-\mathrm{OH}$ dari gugus sitrat serta permukaan magnetit yang berinteraksi dengan air [7].

Berdasarkan karakterisasi menggunakan FTIR, hasilnya mengindikasikan bahwa magnetit tanpa sitrat dan magnetit-sitrat telah berhasil disintesis. Hal ini diindikasikan dengan terbentuknya puncak-puncak spektra inframerah yang karakteristik dari magnetit 
dan adanya gugus fungsi - $\mathrm{OH}$ dan gugus $\mathrm{COO}^{-}$dari sitrat serta ikatan $\mathrm{Fe}-\mathrm{O}$ dan interaksi antara $\mathrm{Fe}$ dari magnetit dengan - $\mathrm{COO}^{-}$dari sitrat.

$\mathrm{Fe}_{3} \mathrm{O}_{4}$ dan $\mathrm{Fe}_{3} \mathrm{O}_{4} @$ sitrat hasil sintesis perlu dilakukan karakterisasi dengan XRD untuk mengidentifikasi jenis mineral magnetik dan ukuran partikelnya. Identifikasi magnetit menggunakan pola difraksi magnetit berdasarkan pola difraksi standar $\mathrm{Fe}_{3} \mathrm{O}_{4}$ JCPDS 00-0011111 dengan puncak karak-teristik magnetit terdapat pada $2 \theta: 30,06^{\circ} .35,45^{\circ} ; 43,04^{\circ} ; 57,17^{\circ}$; dan $62,73^{\circ}$. Adapun hasil karakterisasi XRD pada $\mathrm{Fe}_{3} \mathrm{O}_{4}$ dan $\mathrm{Fe}_{3} \mathrm{O}_{4} @$ sitrat yang dilakukan ditunjukkan pada data pola difraksi Gambar 2.

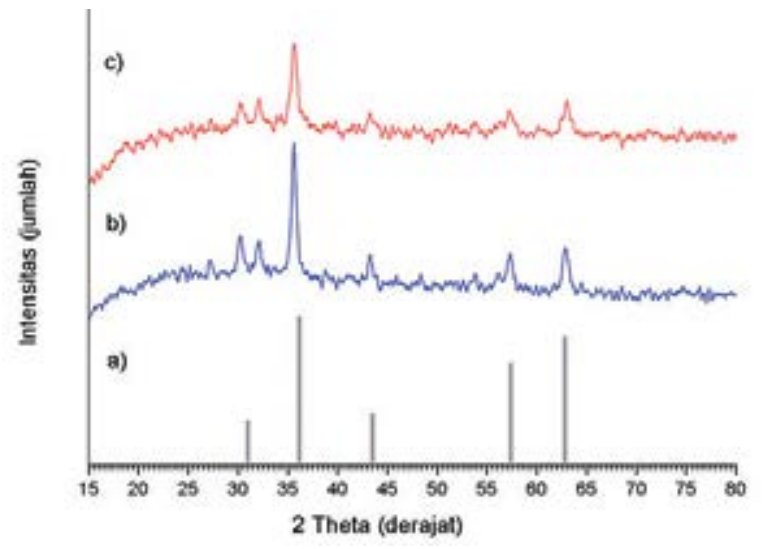

Gambar 2.

Pola Difraksi Sinar-X: a) JCPDS 00-01-1111, b) $\mathrm{Fe}_{3} \mathrm{O}_{4}$ danc) $\mathrm{Fe}_{3} \mathrm{O}_{4} @$ sitrat

Berdasarkan Gambar 2, magnetit yang disintesis memiliki kecocokan dengan puncak-puncak $2 \theta$ pada pola difraksi standar $\mathrm{Fe}_{3} \mathrm{O}_{4}$ JCPDS 00-001-1111. Hal tersebut mengindikasikan bahwa kedua material yang disintesis merupakan magnetit.

Pola difraksi sinar-X pada Gambar 2 juga digunakan untuk menentukan ukuran partikel dan kristalinitas dari magnetit hasil sintesis. Penentuan ukuran kristal magnetit hasil sintesis dengan menggunakan persamaan Deybe-Scherrer pada puncak-puncak $2 \theta$ karasteristik dari magnetit [17].

$D=\frac{0,9 \cdot \lambda}{\beta \cos \theta}$

dengan $\mathrm{D}=$ ukuran Kristal (nm), $\lambda=$ panjang gelombang atom logam yang digunakan (nm), $\beta=$ setengah lebar puncak FWHM (radian), $\theta=$ sudut difraksi Bragg (derajat). Berdasarkan persamaan tersebut, $\mathrm{Fe}_{3} \mathrm{O}_{4} @$ sitrat hasil sintesis memiliki ukuran partikel $17 \mathrm{~nm}$, sedangkan $\mathrm{Fe}_{3} \mathrm{O}_{4}$ memiliki ukuran partikel $23 \mathrm{~nm}$. Ukuran tersebut termasuk ukuran nanomaterial. $\mathrm{Fe}_{3} \mathrm{O}_{4} @$ sitrat memiliki ukuran partikel yanglebih kecil dibandingkan $\mathrm{Fe}_{3} \mathrm{O}_{4}$ tanpa sitrat. Hal ini mengindikasikan bahwa natrium sitrat berhasil mengontrol ukuran pada pembentukan kristral. Hal ini dikarenakan natrium sitrat dapat berfungsi sebagai pengontrol ukuran kristral magnetit pada proses aging [8].

$\mathrm{Fe}_{3} \mathrm{O}_{4}$ dan $\mathrm{Fe}_{3} \mathrm{O}_{4} @$ sitrat hasil sintesis kemudian dikarakterisasi dengan TEM untuk mengetahui dispersinya. Hasil karakterisasi $\mathrm{Fe}_{3} \mathrm{O}_{4}$ dan $\mathrm{Fe}_{3} \mathrm{O}_{4} @$ sitrat hasil sintesis yang dilakukan ditunjukan pada hasil TEM Gambar 3 .

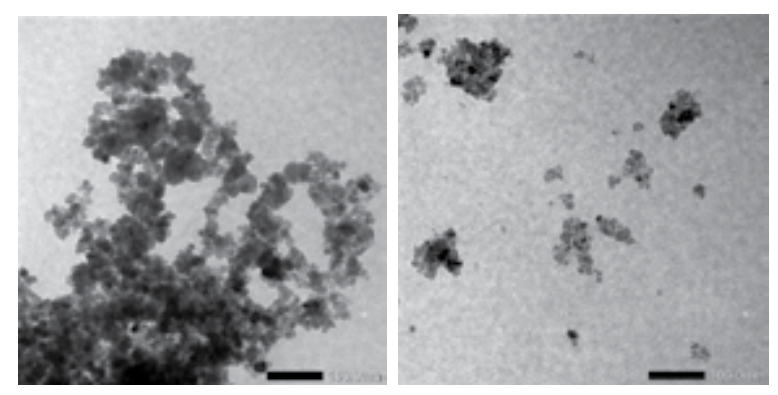

Gambar 3.

Hasil TEM: a) $\mathrm{Fe}_{3} \mathrm{O}_{4}$ dan b) $\mathrm{Fe}_{3} \mathrm{O}_{4} @$ sitrat

Berdasarkan hasil TEM pada Gambar 3, $\mathrm{Fe}_{3} \mathrm{O}_{4} @$ sitrat memiliki dispersi lebih baik dan membentuk agregat dengan ukuran agregat yang lebih kecil dibandingkan $\mathrm{Fe}_{3} \mathrm{O}_{4}$ tanpa sitrat. Hal ini mengindikasikan bahwa natrium sitrat berhasil mengontrol dispersi dari magnetit. Hal ini dikarenakan gugus sitrat bermuatan negatif sehingga menyebabkan tolakan antar gugus sitrat dan menghasilkan jarak antara satu dengan yang lain [8].

$\mathrm{Fe}_{3} \mathrm{O}_{4} @$ sitrat hasil sintesis kemudian diuji aplikasinya dalam mengadsorpsi ion logam emas(III) dari $10 \mathrm{~mL}$ larutan $\mathrm{HAuCl}_{4} 200$ ppm pada $\mathrm{pH}$ 3. Berdasarkan hasil pengukuran AAS, sebanyak $10 \mathrm{mg} \mathrm{Fe}_{3} \mathrm{O}_{4} @$ sitrat mampu mengadsorpsi emas(III) dalam bentuk $\left[\mathrm{AuCl}_{4}\right]^{-}$ sebanyak $(81,554 \pm 1,403)$ ppm. 


\section{SIMPULAN}

Berdasarkan data spektra inframerah, pola XRD, dan gambar TEM, mengindikasikan bahwa $\mathrm{Fe}_{3} \mathrm{O}_{4}$ dan $\mathrm{Fe}_{3} \mathrm{O}_{4} @$ sitrat telah berhasil disintesis. $\mathrm{Fe}_{3} \mathrm{O}_{4} @$ sitrat memiliki ukuran 17 nm yang merupakan ukuran nanomaterial. $\mathrm{Fe}_{3} \mathrm{O}_{4} @$ sitrat memiliki ukuran partikel yang lebih kecil, membentuk agregat yang lebih kecil dan memiliki dispersi yang lebih baik dibandingkan $\mathrm{Fe}_{3} \mathrm{O}_{4}$ tanpa sitrat. $\mathrm{Fe}_{3} \mathrm{O}_{4} @$ sitrat mampu mengadsorpsi emas(III) dalam bentuk $\left[\mathrm{AuCl}_{4}\right]^{-}$sebanyak $(81,554 \pm 1,403) \mathrm{mg} / \mathrm{g}$.

\section{UCAPAN TERIMA KASIH}

Terima kasih ditujukan kepada Prof. Dr. Nuryono, M.S. atas bantuan bahan penelitian yang diberikan.

\section{DAFTAR PUSTAKA}

Okuyama, K. and I.W. Lenggoro. 2003. Preparation of Nanopar-Ticles via Spray Route. Chemical Engineering Science 58(3-6): 537-547.

Khosroshahi, M.E., and L. Ghazanfari. 2010. Preparation and Characterization of Silica-Coated Iron-Oxide Bionanoparticles under $\mathrm{N}_{2}$ Gas. Physica $E$ 42(6): 1824-1829.

Pankhurst, Q.A., J. Connolly, S.K. Jones, and J. Dobson. 2003. Applications of Magnetic Nanoparticles in Biomedicine. Journal of Physics D: Applied Physics 36(13): 167-181.

Blaney, L. 2007. Magnetite $\left(\mathrm{Fe}_{3} \mathrm{O}_{4}\right)$ : Properties, Synthesis, and Applications. Lehigh Review 15: 33-81.

Zhang, Y., Q. Xu, S. Zhang, J. Liu, J. Zhou, H. Xu, H. Xiao, and J. Li. 2013. Preparation of Thiol-Modified $\mathrm{Fe}_{3} \mathrm{O}_{4} @$ $\mathrm{SiO}_{2}$ Nanopar-ticles and Their Application for Gold Recovery From Dilute Solution. Separation and Purification Technology 116: 391-397.

Yantasee, W., C.L. Warner, T. Sangvanich, R.S. Addleman, T.G. Carter, R.J. Wiacek, G.E. Fryxell, C. Timchalk, and M.G. Warner. 2007. Removal of Heavy Metals from Aqueous Systems with Thiol Functiona-lized Superparamagnetic Nano-particles. Environmental Scien-ce and Technology 41(14): 5114-5119.

Farimani, N.S., N.G. Roknabadi, and A. Kazemi. 2013. Study of Structural And Magnetic Properties of Superparamagnetic $\mathrm{Fe}_{3} \mathrm{O}_{4} / \mathrm{SiO}_{2}$ Core-Shell Nanocomposites Synthe-sized with Hydrophilic Citrate-Modified $\mathrm{Fe}_{3} \mathrm{O}_{4}$ Seeds via A Sol-Gel Approach. Physica E 53: 207-216.

Yang, P., Z. Quan, Z. Hou, C. Li, X. Kang, Z. Cheng, and J. Lin. 2009. A Magnetic, Luminescent and Mesoporous CoreShell Structured Compo-site Material as Drug Carrier. Biomaterials 30(27): 4786-4795.

Kim, E.Y., M.S. Kim, J.C. Lee, and B.D. Pandeyc. 2011. Selective Recovery of Gold from Waste Mobile Phone PCBs by Hydrometallurgical Process. Journal of Hazardous Materials 198: 206-215.

Corti, C.W., R.J. Holliday, and D.T Thompson. 2007. Progress Towards The Commercial Application of Gold Catalysts. Topics in Catalysis 44(1-2): 331-343.

Ramesh, Hasegawa, H., Sugimoto, W., Maki, T., and Ueda, K., 2008, Adsorption of Gold(III), Platinum(IV) and Palladium(II) onto Glycine Modified Crosslinked Chitosan Resin, Bioresource Technology, 99(9): 38013809.

Stum, W. And J.J. Morgan. 1996. Aquatic Chemistry: Chemical Equlibria and Rates in Natural Water. $3^{\text {rd }}$ ed. John Wiley and Sons Inc. New York.

Silva-Silva, M.J., O.F Mija-ngos-Ricardez, V. Vázquez-Hipólito, S. MartinezVargas, and J. López-Luna. 2016. Single and Mixed Adsorption of $\mathrm{Cd}(\mathrm{II})$ and $\mathrm{Cr}(\mathrm{VI})$ onto CitrateCoated Magnetite Nanopar-ticles. 
Desalination and Water Treatment, 57(9): 4008-4017.

Jitianu, A., M. Raileanu, M. Crisan, D. Predoi, M. Jitianu, L. Stanciu, and M. Zaharescu. 2006. $\mathrm{Fe}_{3} \mathrm{O}_{4}-\mathrm{SiO}_{2}$ Nanocompo-sites Obtained via Alkoxide and Colloidal Route. Journal of Sol-Gel Science and Technology. 40(2): 317-323.

Hong, R.Y., J.H. Li, H.Z. Li, J. Ding, Y. Zheng, and D.G. Wei. 2008. Synthesis of $\mathrm{Fe}_{3} \mathrm{O}_{4}$ Nanoparticles without Inert Gas Protection Used as Precursors of
Magnetic Fuids. Journal of Magnetism and Magnetic Materials 320(9): 16051614.

Jacintho, G.V.M., A.G. Brolo, P. Corio, P.A.Z. Suarez, and J.C. Rubim. 2009. Structural Investigation of $\mathrm{MFe}_{2} \mathrm{O}_{4}$ ( $\mathrm{M}=\mathrm{Fe}, \mathrm{Co})$ Magnetic Fluids. Journal of Physical Chemistry C 113(18): 76847691.

Wu, S., A. Sun, F. Zhai, J. Wang, W. Xu, Q. Zhang, A.A. Volinsky. 2011. $\mathrm{Fe}_{3} \mathrm{O}_{4}$ Magnetic Nanoparticles Synthesis from Tailings by Ultrasonic Chemical Co-Precipitation. Materials Letters 65(12): 1882-1884. 